\title{
Effect of Soil Properties on Growth of Quercus ilex L. in Humid and Cold Mountains of Morocco
}

\author{
El-Mousaddak Souad $(1)$ and Mohammed Bendriss Amraoui \\ Laboratory of Biotechnology, Environment, Food and Health (LBEFH), Department of Biology, \\ Faculty of Sciences Dhar el Mahraz, Sidi Mohammed Ben Abdellah University, P. O. Box 1796, Atlas, Fez, Morocco
}

Correspondence should be addressed to Mohammed Bendriss Amraoui; mohamed.bendrissamraoui@usmba.ac.ma

Received 19 May 2020; Revised 7 September 2020; Accepted 15 December 2020; Published 28 December 2020

Academic Editor: Maman Turjaman

Copyright (c) 2020 El-Mousaddak Souad and Mohammed Bendriss Amraoui. This is an open access article distributed under the Creative Commons Attribution License, which permits unrestricted use, distribution, and reproduction in any medium, provided the original work is properly cited.

\begin{abstract}
The dependence of oak growth on environmental stressors is fairly well documented, but little is known about the impact of soil type on growth plasticity and as predisposing factors to root branching. Here, we aim to investigate how textural and physicochemical properties of soil affect the growth of Quercus Ilex L. We compare the above- and below-ground growth of saplings on three sandy soil(s) of the Middle Atlas. The textural and physicochemical characterization showed that the soils differed mainly in the gravel, average and fine sand, organic matter, and nitrogen proportions. All tested properties of the three sandy soils do not affect the above-ground growth. The statistical analysis showed that the growth synchronization between the main and lateral roots was affected by the soil type. The statistics showed that the microvariation of the soil texture $(>5,0.2-0.4$, and $0.063-0.2 \mathrm{~mm})$ and the level of nitrogen and not that of the limestone in the soil control the length and thickness of the main root and the production and distribution of biomass of lateral roots. They also showed that these soil properties affect the sink/source competitions between the roots and the leaves and the compensatory growth of roots.
\end{abstract}

\section{Introduction}

Holm oak is a species of evergreen sclerophyllous trees that dominate many forest communities in the Mediterranean basin, characterized by high biodiversity and high human pressure [1]. It shelters a great diversity of endangered species, such as the Spanish imperial eagle and the Iberian lynx and constitutes a species of choice as a nurse harboring many mycorrhizal fungi of high nutritional value [2-4]. The Iberian Peninsula and Morocco constitute $90 \%$ of its global distribution [5-7]. In the last two decades, its presence has increased by more than $71 \%$ [8] due to its use in the restoration of Mediterranean ecosystems as a species adapted to multiple environmental constraints including soil erosion $[9,10]$. Despite this, its growth is conditioned by several factors. Its slow growth and/or high seedling mortality compared with other Mediterranean woody species due to poor seedling quality, post-transplant stress and poor site fertility are causes of planting failure [10]. Similarly, Sheng et al. [11] found that in apple orchards, the degree of apple replant disease in clay loam was most serious, followed by sandy loam and loam.

On the other hand, these factors also make oak seedling growth dependent on changes in root growth as caused by the soil and climate for many species $[12,13]$. Moreover, rhythmic growth of Quercus pubescens roots, which was found to agree with Hevea brasiliensis $[14,15]$ or Quercus alba [16], differed from that of Quercus robur $[17,18]$ in spite of a similar typical rhythm of shoot growth. Some of these authors explained these observed differences by the interspecific variability of Quercus genus and differences in the experimental growth conditions [15]. In the same way, Rozas and Sampedro [19] have found that nutritional deficiencies in the soil aggravated the dieback of Quercus robur in Europe. Furthermore, the development of fine roots under the topsoil by several desert species has been considered as a strategy to avoid the drying of the topsoil between rainy episodes [20]. Likewise, other authors have observed that the 
soil texture has also been related to soil and plant water relations with species required to reach lower minimum water potential to be able to access tightly bound water typical of fine-textured soils [21-23]. Wiecheteck et al. [24] reported that wilting depends on soil texture, with an occurrence of wilting at higher matric potentials for sandy soils than for clay soils. As these are known to heavily affect plant water availability, local soil profiles and local soil texture influenced the root architecture [12] and may also interact with plant root differently depending on soil texture [25]. Moreover, Rafique et al. [26] found that biochar and soil type interactions may develop a unique behavior of phosphorus uptake, root colonization, plant growth, and root attributes.

Apart from this, little is known about Quercus ilex L., although it dominates many forest communities in the Mediterranean basin [10]. Even if recent studies have shown leaf defense strategies on oxidative stress and adaptations to $\mathrm{N}$ deficiency and toxicity of $Q$. ilex $\mathrm{L}$. $[1,10]$ and soil typespecific growth patterns of Quercus robur L. [27], few attention was attempted to the impact of soil type on the shoot and root branching relations, which should lead to improved plantation establishment, and as predisposing factors to restoration success. We aim to investigate how textural and physicochemical properties of humid and cold mountain soil of Morocco affect growth of Q. ilex $\mathrm{L}$.

\section{Materials and Methods}

2.1. Soil Sampling Sites. The soils for the study were collected from two distant forests of the Ifrane region of the Moroccan Middle Atlas. These forests are characterized by a humid and cold climate of the Mediterranean mountain type (Table 1). At the level of the Zerrouka oak grove, two soils were sampled: Zerrouka (a) and Zerrouka (b), and in the oak grove mixed with the Ras el ma cedar, only one soil was harvested. About $25 \mathrm{~kg}$ of each soil at a depth of $20 \mathrm{~cm}$ was sampled over an area of $1 \mathrm{~m}^{2}$ after removing the fraction of the litter and the humus above the soil surface. These three soils were named according to the soil rating established by Viscarra Rossel et al. [28].

2.2. Fertility of the Soils Studied. Total organic soil carbon (TOC) was determined according to the method of Walkley and Black [29] after drying and sieving the soil to $0.4 \mathrm{~mm}$. The content of organic matter in the soil (OM) was determined indirectly by the equation: $\%$ of OM $/ \%$ of TOC $=1.72$. The total nitrogen content of the soil was estimated by the colorimetric method of Berthelot [30], after mineralization of $100 \mathrm{mg}$ of soil by the mixture of sulfuric acid and hydrogen peroxide according to the method of Kjeldahl [31]. The water $\mathrm{pH}$ value was determined $24 \mathrm{~h}$ after stirring for $10 \mathrm{~min}$ an amount of $20 \mathrm{~g}$ sieved $2 \mathrm{~mm}$ soil in a volume of $50 \mathrm{~mL}$ of boiling distilled water. The $\mathrm{C} / \mathrm{N}$ ratio was estimated by the ratio: (\% TOC)/(\% Kjeldahl nitrogen). The carbon in calcium carbonate was released in the form of $\mathrm{CO}_{2}$ from the soil in an acid medium and then measured by the method of Martin Rubio [32] and expressed in $\mathrm{mg}$ of $\mathrm{CaCO}_{3}$ per gram of soil. These soil analyses were repeated three times.
2.3. Particle Size Properties of Soils. The particle size characteristics of the soils were determined according to Blott and Pye [33] after drying and passage of three samples of $100 \mathrm{~g}$ of each soil through a series of sieves with mesh diameters of 5, 0.4, 0.2, 0.063, and $0.04 \mathrm{~mm}$. The sieve mesh diameters were chosen to identify the differences between the soils from the point of view of grain size between $0.4 \mathrm{~mm}$ and $0.04 \mathrm{~mm}$ as found mainly in fine-textured soils affecting water retention of the ground [21-23].

2.4. Green Oak Growing Conditions. Acorns of the same size from the Zerrouka oak grove (2014) are soaked in water for $48 \mathrm{~h}$ and transferred to damp paper until the radicle appears. The sprouted acorns were sown in containers in the form of a parallelepiped $30 \mathrm{~cm}$ high, $6 \mathrm{~cm}$ wide and long, and $1080 \mathrm{~cm}^{3}$ in volume. The culture was carried out in a ventilated growth chamber of $2 \times 6$ meters at a humidity of $70 \%$, a temperature of $24^{\circ} \mathrm{C}$ at night and $32^{\circ} \mathrm{C}$ during the day, a photoperiod of $16 / 8 \mathrm{~h}$, and a light intensity higher than $70 \mu \mathrm{mol} \cdot \mathrm{s}^{-1} \cdot \mathrm{m}^{-2}$ produced by cool daylight $6400 \mathrm{~K} 2700 \mathrm{Lm}$ bulbs suspended $30 \mathrm{~cm}$ from the top of the seedlings at the time of sowing. The seedlings were irrigated with running water every three days.

2.5. Seedling Treatments and Analyses. At the age of two months, three seedlings with a main root of similar length $(26$ to $30 \mathrm{~cm}$ ) were selected after their harvest and the different organs were separated for each soil. To assess the variation in the distribution of secondary roots along the main root, the root system was carefully cleared from the ground and the main root was cut into $2 \mathrm{~cm}$ fragments from the root stem transition zone to the root tip. The first fragment collected is from 0 to $2 \mathrm{~cm}$, and the last, from $x$ to $y$ $\mathrm{cm}$, with $y=$ length value in $\mathrm{cm}$ of the main root (lv) and $x=l v$ minus $2 \mathrm{~cm}$. To properly evaluate the distribution of the lateral roots statistically, the determination of the dry mass and the water content of these roots carried by the main root was achieved only from fragment 0 to $2 \mathrm{~cm}$ to fragment 24 to $26 \mathrm{~cm}$, while the estimation of the thirteen green oak growth parameters described in Figure 1 and Table 2 was accomplished on the whole organ including the main root and the secondary roots of the seedlings.

The length was determined to the nearest $0.25 \mathrm{~mm}$ by double decimeter. The number was evaluated per count. The leaves were scanned, and the leaf area was calculated by ImageJ software (version 1.50i, 2016). The dry matter mass was determined after drying the samples at $70^{\circ} \mathrm{C}$ for 48 hours and weighed with a precision balance of $1 \mathrm{mg}$. The determined dry mass values are expressed in $\mathrm{mg} /$ organ, $\mathrm{mg} /$ fragment, $\%$ of the total whole seedling dry mass, $\%$ of the total root dry mass, and $\%$ of the total main root dry mass. The water content was estimated according to the equation: (FW $-\mathrm{DW}) \times 100 /(\mathrm{FW})$, with FW: fresh weight and DW: dry weight.

2.6. Statistical Analyses. The data obtained with three repetitions by growth and soil parameters were subjected to the Levene variance homogeneity test and the Shapiro-Wilk normality test. Analysis of variance (ANOVA) was used to 
TABLE 1: Environmental conditions of sampled soils of Quercus ilex L.

\begin{tabular}{|c|c|c|c|c|c|c|c|}
\hline Forests & Latitude & Longitude & $\begin{array}{l}\text { Altitude } \\
\text { (m) }\end{array}$ & $\begin{array}{c}\text { Average total annual } \\
\text { precipitation }\end{array}$ & $\begin{array}{c}\text { Average annual } \\
\text { temperature }\end{array}$ & Parent rock & Substrate richness \\
\hline Zerrouka & $33^{\circ} 32^{\prime} 25.16^{\prime \prime} \mathrm{N}$ & $5^{\circ} 06^{\prime} 03.67^{\prime \prime} \mathrm{W}$ & 1,667 & $964(\mathrm{~mm} / \mathrm{y})$ & 11.8 & Dolomitic & Carbonate of calcium \\
\hline
\end{tabular}

Data from the climatological station of Ifrane Airport (east of the basin, period 1973-2010).

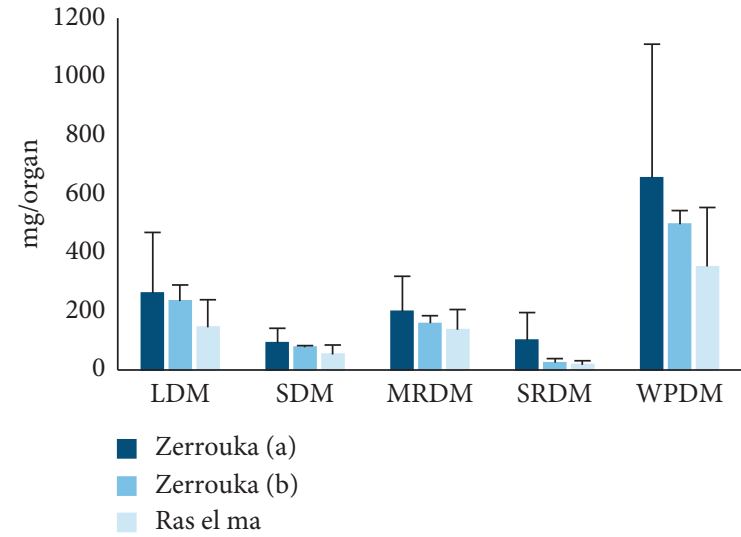

(a)

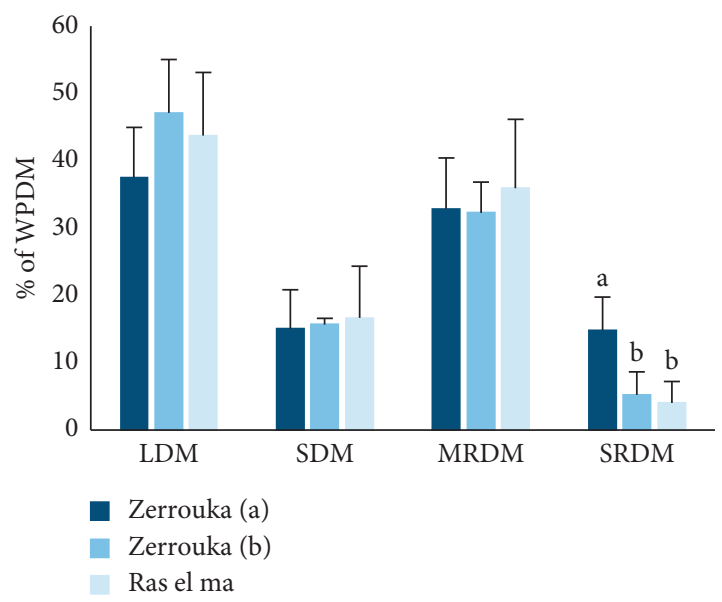

(c)

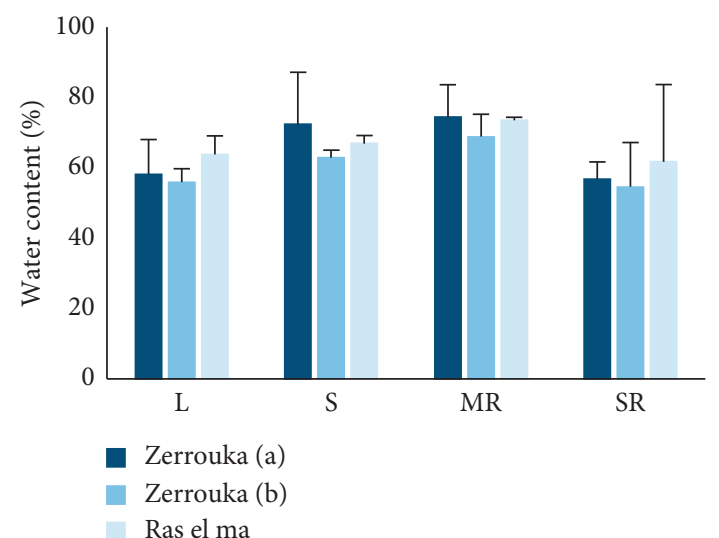

(b)

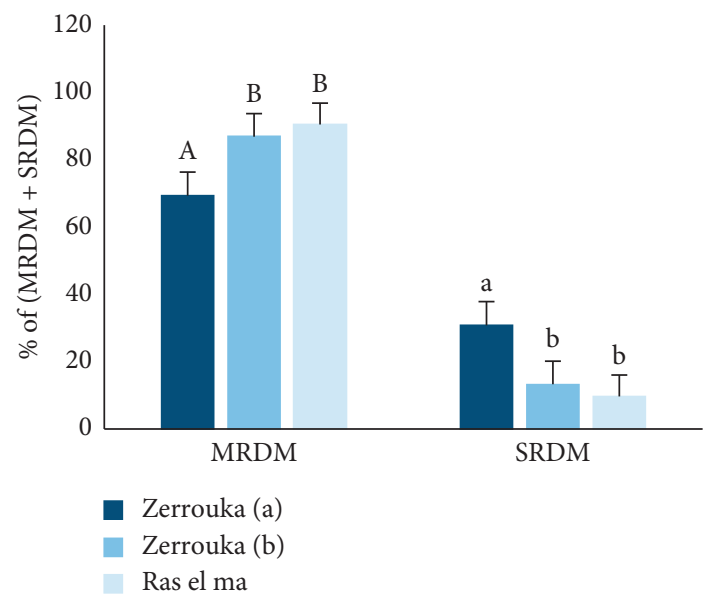

(d)

FIGURE 1: Growth of seedling organs: (a) Dry mass in mg/organ, (b) water content in \%, (c) dry mass in \% of dry mass of the whole plant, and (d) dry mass in \% of dry mass of all the roots of the plant. The different letters in upper and lower case indicate the significant differences $(P<0.05, n=3)$. The absence of letter indicates no significant difference at $P<0.05$ except for SDM. LDM: leaf dry mass; SDM: stem dry mass; MRDM: main root dry mass; SRDM: secondary root dry mass; WPDM: whole plant dry mass; L: leaves, S: stem; MR: mean root; SR: secondary roots.

TABLE 2: Variation of seedling growth parameters.

\begin{tabular}{lccc}
\hline Parameters & Zerrouka (a) & Zerrouka (b) & Ras el ma \\
\hline MRL $(\mathrm{cm})$ & $26.7^{\mathrm{a}} \pm 1.2$ & $29.3^{\mathrm{ab}} \pm 1.2$ & $32^{\mathrm{b}} \pm 3.5$ \\
SL $(\mathrm{cm})$ & $8.8^{\mathrm{a}} \pm 2.8$ & $9.1^{\mathrm{a}} \pm 0.8$ & $7.2^{\mathrm{a}} \pm 2.4$ \\
SRL $\left(\mathrm{cm} \cdot \mathrm{mg}^{-1}\right)$ & $0.2 \pm 0.1$ & $0.2 \pm 0.0$ & $0.3 \pm 0.1$ \\
LA $\left(\mathrm{cm}^{2}\right)$ & $32.8^{\mathrm{a}} \pm 19.8$ & $33.8^{\mathrm{a}} \pm 9.2$ & $26.7^{\mathrm{a}} \pm 6.4$ \\
SRN & $177.3^{\mathrm{a}} \pm 26.1$ & $88.3^{\mathrm{b}} \pm 33.0$ & $75.7^{\mathrm{b}} \pm 13.5$ \\
LN & $9.7 \pm 4.9$ & $8.7 \pm 0.6$ & $7.3 \pm 4.9$ \\
LSM $\left(\mathrm{mg}^{-\mathrm{cm}^{-2}}\right)$ & $7.2^{\mathrm{a}} \pm 1.7$ & $7^{\mathrm{a}} \pm 0.6$ & $5.1^{\mathrm{a}} \pm 2.3$ \\
LA/RL $\left(\mathrm{cm}^{2} \cdot \mathrm{cm}^{-1}\right)$ & $1.2^{\mathrm{a}} \pm 0.8$ & $1.2^{\mathrm{a}} \pm 0.4$ & $0.8^{\mathrm{a}} \pm 0.1$ \\
\hline
\end{tabular}

Values marked with different letters indicate a significant difference $(P<0.05, n=3)$. The absence of letter indicates that the parameters do not follow a normal law. MRL: main root length; SL: stem length; SRL: specific root length (length of the main root on its dry mass); LA: leaf area; SRN: secondary root number; LN: leaf number; LSM: leaf specific mass (mass of seedling leaves on their surfaces); LA/RL: leaf area/main root length. 
compare the means by Fisher's post hoc test of the least significant difference (LSD) at $P<0.05$. Pearson correlation coefficients were calculated with a 5 and $1 \%$ risk of error using nine repetitions for each parameter. All of these statistics were compiled using IBM SPSS Statistics (version 20.0, 2011).

\section{Results}

Ras el ma soil contains mainly coarse material of the fractions $(>5 \mathrm{~mm})$ and $(0.063-0.2 \mathrm{~mm})$ with 32 and $28 \%$, respectively. Zerrouka soil (a) has high values of the fractions $(0.2-0.4 \mathrm{~mm})$ and $(0.063-0.2 \mathrm{~mm})$ with 14 and $39 \%$, respectively. The Zerrouka soil (b) is characterized by low average values of these fractions. The values of the fractions $(0.4-5 \mathrm{~mm})$ and $(0.04-0.063 \mathrm{~mm})$ do not follow a normal law and do not allow the three soils to be distinguished. The fractions $(0.2-0.4 \mathrm{~mm})$ and $(0.063-0.2 \mathrm{~mm})$ significantly distinguish the three soils from each other. The fraction ( $>5 \mathrm{~mm}$ ) of the Ras el ma soil differs significantly from that of the Zerrouka (a) and Zerrouka (b) soils (Table 3).

The soil analyses made it possible to chemically characterize the three soils studied. Zerrouka soils have the most total nitrogen, while Ras el ma soil has the lowest total organic carbon $(0.56 \%), \mathrm{C} / \mathrm{N}$ ratio (1.4), and organic matter $(0.96 \%)$ compared with other soils. The $\mathrm{pH}$ is basic in all soils, with a slight superiority to Zerrouka (a) compared with the others. Limestone is very weak in the soil of Zerrouka (b), intermediate in Zerrouka (a), and abundant in Ras el ma. According to the Viscarra Rossel et al. notation of the soil [28], the soil of Zerrouka (a) has an ivory black color, while the soil of Zerrouka (b) is burnt umber, and that of Ras el ma is burnt sienna (Table 4).

Total organic carbon (TOC) and organic matter (OM) do not follow a normal law. The total nitrogen of the three soils was significantly different. The $\mathrm{C} / \mathrm{N}$ ratio significantly discriminated Zerrouka (b) from Ras el ma and Zerrouka (a). Limestone significantly distinguished the three soils. The $\mathrm{pH}$ showed no significant difference between the three soils (Table 4).

The fraction of average sand $(0.2-0.4 \mathrm{~mm})$ was positively correlated with $\mathrm{pH}$ and total nitrogen and negatively correlated with the fraction of gravel $(>5 \mathrm{~mm})$ and limestone. The fraction $(>5 \mathrm{~mm})$ was positively correlated with limestone and negatively correlated with total nitrogen and $\mathrm{C} / \mathrm{N}$ ratio. The limestone was negatively correlated with the $\mathrm{C} / \mathrm{N}$ ratio.

3.1. Seedling Growth. The amount of dry mass and the water content of each organ of the seedlings of the three soils were similar (Figures 1(a) and 1(b)). In return, the soil of Zerrouka (a) increased significantly the secondary root proportion to $15 \%$ of the dry mass of the whole plant but did not affect the other organs compared with other soils (Figure 1(c)). This soil increased significantly the secondary root proportion to $31 \%$ but reduced that of the main root to $69 \%$ of the total mass of the roots compared with the others (Figure $1(\mathrm{~d})$ ). A high number of secondary roots (SRN) with a short length of the main root (MRL) were observed on the soil of Zerrouka (a) compared with the other soils (Table 2).

Statistics of the main and secondary root proportions and the number of secondary roots revealed a significant effect of the soil between Zerrouka (a) and the other soils (Figures 1(c) and 1(d) and Table 2). However, the main root length showed significantly a soil effect only between Zerrouka (a) and Ras el ma (Table 2).

A significant negative correlation was observed between the main root length and nitrogen, the soil fractions (>5 mm) and (0.2-0.4 mm), while the number of secondary roots was found to be positively correlated with nitrogen and the Silt-clay fraction $(<0.04 \mathrm{~mm})$.

3.2. Root Growth. The water content of all fragments of the main root without secondary roots was constant and similar in the three soils (data not shown). More intensely water content fluctuated rhythmically between the secondary roots of the fragments in the soils of Ras el ma and Zerrouka (b) but remained relatively constant in the soil of Zerrouka (a). It was significantly high in Ras el ma soil and low in Zerrouka soil (b) only in fragment 14 to $16 \mathrm{~cm}$ (Figure 2).

The depth distribution of the root mass decreased slightly along the main root (Figure 3 ). The proportion of the main root mass of fragment 0 to $2 \mathrm{~cm}$ was 17,31 , and $35 \%$ in Zerrouka (a), Zerrouka (b), and Ras el ma soils, respectively. The main root mass proportion at Zerrouka soil (a) increased from fragment 12 to $14 \mathrm{~cm}$ to fragment 16 to $18 \mathrm{~cm}$ compared with other soils (Figure 3(a)). The main root mass from the root stem transition zone to about $6 \mathrm{~cm}$ deep in the soil was relatively similar for the three soils but grown more beyond this region in the Zerrouka soil (a) from fragment 6 to $8 \mathrm{~cm}$ to fragment 16 to $18 \mathrm{~cm}$ (Figure $3(\mathrm{~b})$ ).

In general, the depth distribution of the lateral root mass was alternative along the main root. Zerrouka soil (a) induced an increase in the proportion of the secondary root mass between the fragments 4 to 6 and 14 to $16 \mathrm{~cm}$ compared with the other soils (Figure 4(a)). The three soils affected the secondary root mass in the same way as it was evaluated in \% of the total main root mass (Figure 4(b)).

The extent of the secondary root production area on the main root was important in all soils, however their number was more concentrated from the root stem transition zone to the fragment 14 to $16 \mathrm{~cm}$ deep in Zerrouka (a) soil. The seedlings grown on Zerrouka (b) and Ras el ma soils regularly distributed their lateral roots in a homogeneous and relatively constant way along the main root (Figure 5).

The statistic test showed a significant effect between Zerrouka (a) and the other soils on the main root mass proportion in fragments 0 to 2,12 to 14,14 to 16 and 16 to $18 \mathrm{~cm}$ (Figure 3(a)). This soil also significantly affected the main root mass from the fragment 6 to $8 \mathrm{~cm}$ to the fragment 16 to $18 \mathrm{~cm}$ except in fragment 14 to $16 \mathrm{~cm}$ compared with the other soils (Figure 3(b)). The secondary root proportion of the fragments in \% of the total main root mass showed a significant soil effect between Zerrouka (a) and the other soils on fragments 4 to 6,12 to 14 and 14 to $16 \mathrm{~cm}$ and between Zerrouka (a) and Zerrouka (b) on fragment 8 to 
TABLE 3: Particle size characteristics of soils.

\begin{tabular}{|c|c|c|c|c|c|c|}
\hline \multicolumn{7}{|c|}{ Texture (\%) } \\
\hline \multirow{2}{*}{ Site } & \multicolumn{6}{|c|}{ Fraction of grain sizes $(\mathrm{mm})$} \\
\hline & $>5$ & $0.4-5$ & $0.2-0.4$ & $0.063-0.2$ & $0.04-0.063$ & $<0.04$ \\
\hline Zerrouka (a) & $17.54^{\mathrm{a}} \pm 1.82$ & $15.42 \pm 1.42$ & $14.21^{\mathrm{a}} \pm .07$ & $39.07^{\mathrm{a}} \pm 4.09$ & $7.78 \pm 0.40$ & $6.91^{\mathrm{a}} \pm 2.78$ \\
\hline Zerrouka (b) & $18.88^{\mathrm{a}} \pm 3.54$ & $46.18 \pm 8.09$ & $11.57^{\mathrm{b}} \pm 1.50$ & $17.75^{\mathrm{b}} \pm 2.73$ & $2.84 \pm 0.69$ & $2.46^{\mathrm{a}} \pm 2.69$ \\
\hline Ras el ma & $31.75^{\mathrm{b}} \pm 1.80$ & $23.31 \pm 0.65$ & $7.01^{c} \pm 0.29$ & $27.77^{\mathrm{c}} \pm 1.02$ & $6.79 \pm 0.16$ & $3.31^{\mathrm{a}} \pm 1.02$ \\
\hline
\end{tabular}

Values marked with different letters indicate a significant difference $(P<0.05, n=3)$. The absence of letter indicates that the soil fractions do not follow a normal law.

TABle 4: Chemical characteristics of soils.

\begin{tabular}{lccccccc}
\hline & Water $\mathrm{pH}$ & $\mathrm{N}\left(\mathrm{mg}^{\mathrm{a}} \mathrm{g}^{-1}\right)$ & TOC $(\%)$ & $\mathrm{C} / \mathrm{N}(\% / \%)$ & OM (\%) & ${\text { Limestone }\left(\mathrm{mg} \cdot \mathrm{g}^{-1}\right)}_{\text {Soil color }}$ \\
\hline Zerrouka (a) & $8.13^{\mathrm{a}} \pm 0.34$ & $12.16^{\mathrm{a}} \pm 0.41$ & $2.4 \pm 0.24$ & $1.98^{\mathrm{a}} \pm 0.23$ & $4.13 \pm 0.41$ & $171.79^{\mathrm{a}} \pm 42.38$ & Ivory black \\
Zerrouka (b) & $7.85^{\mathrm{a}} \pm 0.13$ & $7.96^{\mathrm{b}} \pm 0.76$ & $2.24 \pm 0.18$ & $2.85^{\mathrm{b}} \pm 0.5$ & $3.85 \pm 0.31$ & $31.23^{\mathrm{b}} \pm 28.47$ & Burnt umber \\
Ras el ma & $7.71^{\mathrm{a}} \pm 0.27$ & $3.96^{\mathrm{c}} \pm 0.13$ & $0.56 \pm 0.14$ & $1.4^{\mathrm{a}} \pm 0.30$ & $0.96 \pm 0.24$ & $504.70^{\mathrm{c}} \pm 42.38$ & Burnt sienna \\
\hline
\end{tabular}

Values marked with different letters indicate a significant difference $(P<0.05, n=3)$. The absence of letter indicates that the soil traits do not follow a normal law. N: total nitrogen content of the soil; TOC: total organic soil carbon; $\mathrm{C} / \mathrm{N}: \mathrm{C} / \mathrm{N}$ ratio; OM: content of organic matter in the soil.

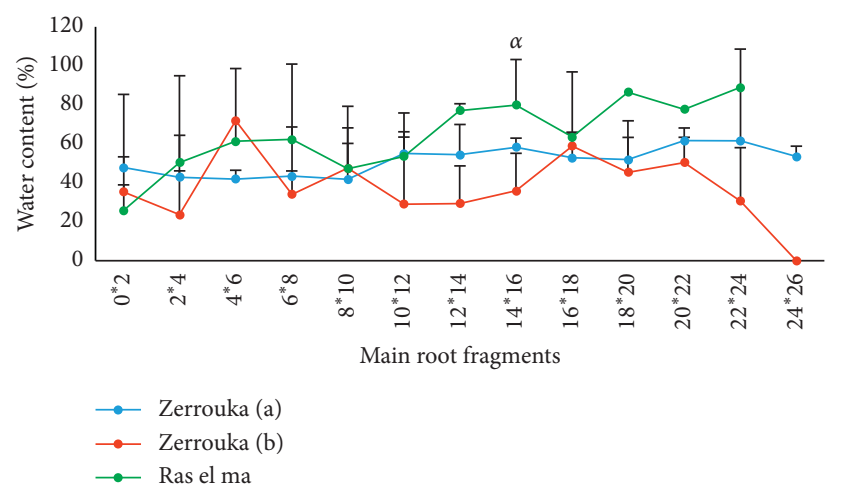

FIGURE 2: Distribution of water in the secondary roots attached to the fragment of the main root. $0 * 2$ means fragment 0 to $2 \mathrm{~cm}$. The values marked with $\alpha$ indicate at least one significant difference at the fragment level $(P<0.05, n=3)$.

$10 \mathrm{~cm}$ (Figure 4(a)). Similarly, a significant effect between Zerrouka (a) and Zerrouka (b) was observed in the secondary root mass in fragments 4 to 6,12 to 14 and 14 to $16 \mathrm{~cm}$ (Figure 4(b)). A significant soil effect between Zerrouka (a) and the other soils was observed in the secondary root abundance between fragments 2 to $4 \mathrm{~cm}$ and 12 to $14 \mathrm{~cm}$. The same effect was manifested between Zerrouka (a) and Zerrouka (b) in fragment 10 to $12 \mathrm{~cm}$ and Ras el ma in fragment 14 to $16 \mathrm{~cm}$ and between Zerrouka (b) and Ras el ma in fragment 2 to $4 \mathrm{~cm}$ (Figure 5).

\section{Discussion}

4.1. Characterization of the Soil. The tree sites in Morocco under humid and cold climate have sandy loamy soils with more gravel. The soil of Zerrouka (a) has a black ivory color, more $\mathrm{N}$ and sands (0.2-0.4 and 0.063-0.2 mm), and much organic matter as Zerrouka (b), but on the other hand, Ras el ma, which is of burnt sienna color, has a very low organic matter content and much more gravel $(>5 \mathrm{~mm})$ and limestone. This observation shows that the color may be due to the organic matter and the other soil properties. This agrees with the study by Fernandez et al. [34] and Schulze et al. [35] in which the effect of organic matter was weak on soils with many different properties but important when these properties were similar. Equivalently, an effect of organic matter on the soil properties and its color has been found to change with its quantity, nature, and depth in the ground [36-38]. Since a negative relationship of the gravel and limestone with the sand, $\mathrm{N}$, and $\mathrm{C} / \mathrm{N}$ and a difference in quantity and quality of the organic matter between our soils were found, the soil color mainly here was not due to organic matter.

4.2. Effect of Soil on Seedlings. Growth variations can be interpreted by carbohydrate, auxin, and water limitations according to the sink/source relationship between roots and leaves and the rhythmicity of the shoots $[15,39]$. The study on Q. pubescens by Willaume and Pagès [15] showed that the root elongation was depressed during the expansion of the second flush of the leaves, with a more pronounced response from the secondary roots. In contrast, the results of Harmer [17], which have pointed out that the root is not linked to the rhythmic growth and that the relationship between the main and lateral roots changes during growth of $Q$. robur, contradict the dependence of the two types of roots to the leaves. In this study, this link varies with soil texture and the nutrient level. For example, on the soils of Zerrouka (b) and Ras el ma compared with the soil of Zerrouka (a), the main root of Holm oak was increased in length and not in biomass during the expansion of the leaves, but a more pronounced decline of the secondary roots in biomass and number occurred, suggesting a linkage between shoot growth and lateral roots similar to Q. pubescens and different to Q. robur $[15,17]$.

In accordance with the sink/source hypothesis, the growth of leaves and main root at the expense of secondary roots showed that the competition is more severe on Zerrouka (b) and Ras el ma soils and the mature leaves have increased their allocation of resources to the youngest ones 


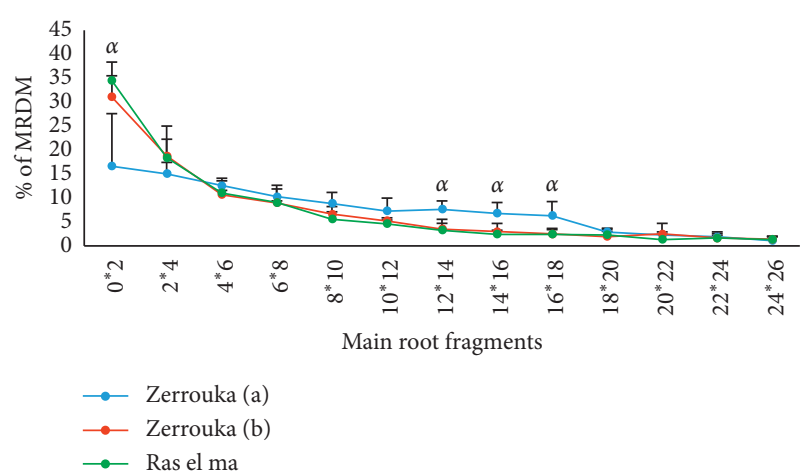

(a)

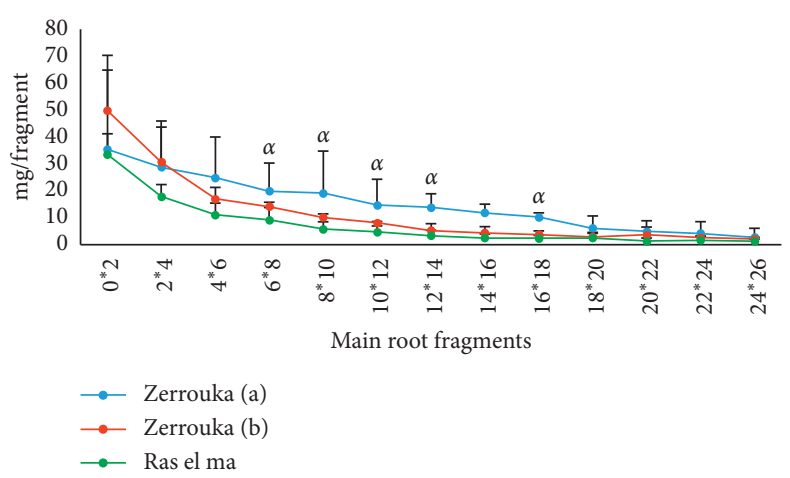

(b)

FiguRe 3: Distribution of main root dry mass without secondary roots in the fragments. (a) Dry mass in \% of all the main root dry mass (MRDM). (b) Dry mass in mg/fragment. $0 * 2$ means fragment 0 to $2 \mathrm{~cm}$. The values marked with $\alpha$ indicate at least one significant difference at the fragment level $(P<0.05, n=3)$.

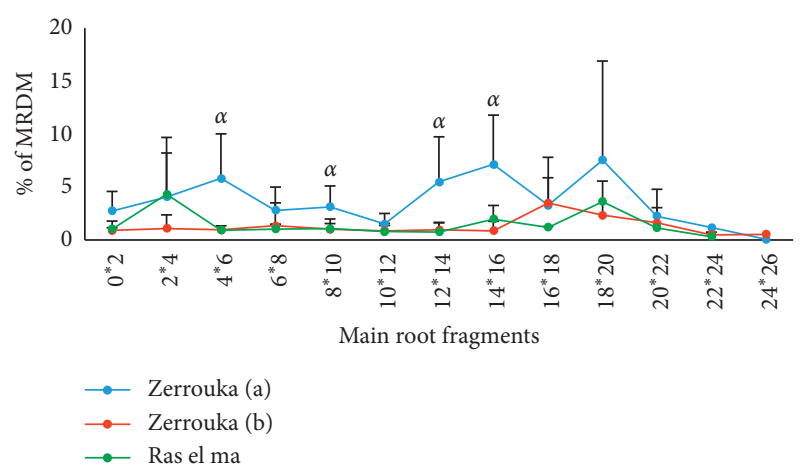

(a)

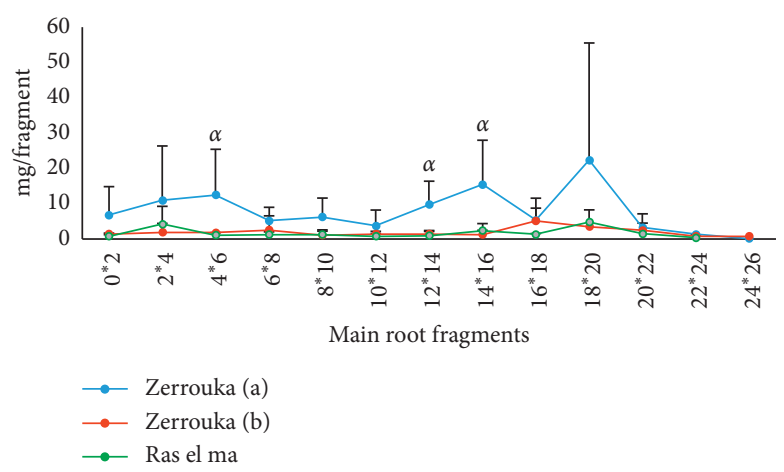

(b)

FIGURE 4: Distribution of dry matter of secondary roots attached to the fragment of the main root. (a) Dry mass in \% of the main root dry mass (MRDM). (b) Dry mass in $\mathrm{mg} /$ fragment. $0 * 2$ means fragment 0 to $2 \mathrm{~cm}$. The values marked with $\alpha$ indicate at least one significant difference at the fragment level $(P<0.05, n=3)$.

at the cost of the decline in the growth of their lateral roots. This agrees with the major influence of carbohydrate intake on root development. Studies with mineral and carbon alterations of the source-sink relationships of carbohydrates have shown that these modifications impair the development of the roots and particularly that of the lateral roots $[10,15,39]$. The significant development of secondary roots in biomass and number in spite of a slight reduction in leaves on Zerrouka soil (a) compared with other soils was due to a compensation for the increasing production cost of the lateral roots on Zerrouka (a) because the seedlings invest more in their lateral roots. This only took place on Zerrouka soil (a), even if the seedlings of all soils have similar lower values of leaf specific mass ascribing high photosynthetic activity [1] to meet the carbon requirements of the roots and young leaves. Data from Hamer et al. [12] that the species generally grown in coarse-textured soil had a lower leaf specific mass than that of soils with intermediate and fine texture confirm the low values of leaf specific mass found here, despite all the soils having a coarse texture significantly different. This supports the idea that the lateral root growth compensation may be due to the coarse texture effect on leaf specific mass as found in other studies [12, 40].

The advantages of organic matter on the plant development have been found to change with its characteristic, soil type, and species [26, 36-38, 41]. Allison [42] observed that organic matter has a major effect on filtration, water retention, and root penetration by the formation of aggregates with the soil grains inducing better growth of secondary roots such as was produced in Zerrouka soil (a) rich in organic matter, fine grains of sand, and nutrients. This suggests a potential interaction of soil factors on oak growth supported by the correlations found between the fraction $(0.2-0.4 \mathrm{~mm})$ and nitrogen.

On the one hand, the significant increase in the abundance of secondary roots (SRN) and reduction in the length of the main root (MRL) by soil, and on the other hand, the significant relationships of SRN and MRL with nitrogen and the textural fractions of the soil $(>5 \mathrm{~mm}),(0.2-0.4 \mathrm{~mm})$, and $(<0.04 \mathrm{~mm})$ show that these two abiotic factors simultaneously modulate the root system development of $Q$. ilex L. This agrees with data of Uscola et al. [10] who showed that 


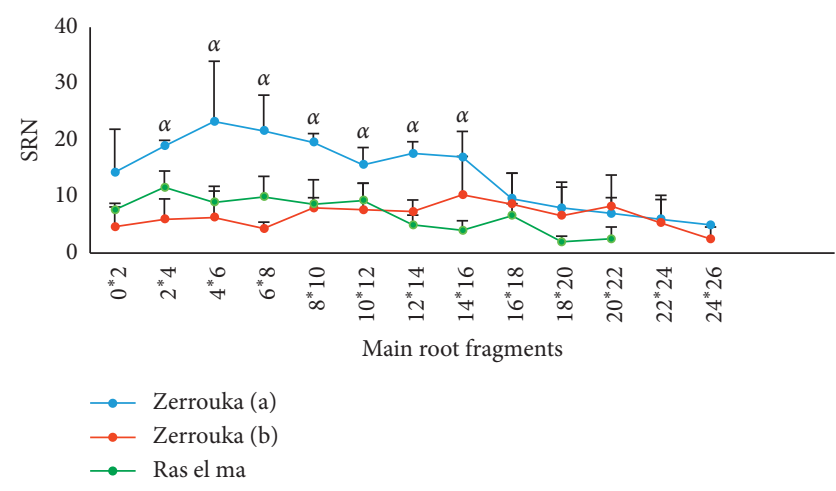

FIGURE 5: Variation in abundance of secondary roots (SRN) by fragment of the main root. $0 * 2$ means fragment 0 to $2 \mathrm{~cm}$. The values marked with $\alpha$ indicate at least one significant difference at the fragment level $(P<0.05, n=3)$.

the nitrogen status of the soil is essential for the success of holm oak plantations because its sufficiency level is still relatively high compared with report of Quercus spp. from other biomes. The interactions of soil texture with nutrients on SRN and MRL of Q. Ilex agree with data of Hamer et al. [12] and Mohamed et al. [13] on the interaction of the soil texture and temperature with the climate on lateral root initiation and elongation rate. In return, a soil root interaction has also been proved by the deep impact of plant rhizosphere on limestone-derived soil [43] and clay soil more than that on a sandy loam [25]. These findings are approved by many data [44-46], which showed that depending on the texture, root growth, apparent density, and species, the porosity of the soil in the rhizosphere changes.

4.3. Effect of Soil on Root Distribution. The Q. ilex L. seedlings observed had a homogeneous leaf development and a heterogeneous root development between the soils in the deep showed by the analysis of the root fragment. The main root growth alternated weakly and slowed down but does not pulled over in depth, while the evolution of the lateral root growth was very complex, suggesting that the lateral roots followed more the known rhythmic development of the carbohydrate source leaves than the main root [15].

The alternative growth of the lateral roots of $Q$. ilex L. agrees with that of Q. pubescens [15] and Q. alba [16] but differs from that of $Q$. robur $[17,18]$. These differences can be explained not only by an interspecific variability but also by a difference in expression of the shoot growth rhythmicity due to the conditions of experiment used by these researchers. Moreover, the lateral root alternation has not always been directly linked to soil proprieties [10-12, 15, 24-27] and the information available on the texture effect on distribution of these root type is very scarce. In this study, the lateral root alternation was found to change not only according to the soil but also with the growth parameter; it manifested itself well in terms of water status but not in terms of biomass in Ras el ma and Zerrouka (b) soils and vice versa for Zerrouka soil (a). The increase in the main root length in Zerrouka (b) and Ras el ma soils suggests that the soil modulate the lateral root water fluxes making them a water reservoir to support the elongation of the main root.

On Zerrouka soil (a), even if the seedlings did not develop their main root down fast, they invested significantly a greater proportion of their resources in the main root increasing its biomass and consequently its thickness between the root fragments 6 to 8 and 16 to $18 \mathrm{~cm}$. This was due to the abundance of the fine grains $(0.2-0.4 \mathrm{~mm})$ and $(0.063-0.2 \mathrm{~mm})$ over coarse ones $(>5 \mathrm{~mm})$ and $(0.4-5 \mathrm{~mm})$ in Zerrouka soil (a) unlike other soils. This observation agrees with previous studies, which showed an association of the root elongation decline with radial expansion in high soil compaction [47]. In this soil, the secondary roots between the root fragments 2 to $4 \mathrm{~cm}$ and 14 to $16 \mathrm{~cm}$ increased the exploration area in this depth. A plausible explanation for these data can be found in the study by Hamer et al. [12] who showed that all coarse-textured species in the dry and humid climate, unlike fine-textured species, allocate more of their roots in the topsoil to collect nutrients and water from a large area of the soil before quickly moving on to the development of the main root and dry out later during the dry month.

On Ras el ma and Zerrouka (b) soils, seedlings have a long main root with a biomass similar to that of Zerrouka soil (a) seedlings but invested few lateral roots in the topsoil between root fragments 4 to $6 \mathrm{~cm}$ and 16 to $18 \mathrm{~cm}$. This indicates that in these two soils, the roots lower in the profile were thinner roots. Since in this study we worked with main root fragments of the same length $(2 \mathrm{~cm})$, the decrease in depth of the main root thickness can only be due to the biomass decline of main root fragments and not to their length. This tendency is shown in the sandy red soil response of species typically growing in fine texture with a higher percentage of root mass deeper in the soil observed only in the length and not in the dry mass of the roots [12]. Conversely to this, the species that preferred the coarse texture responded similarly to Zerrouka soil (a) seedlings, suggesting that the acorn of Holm Oak sampled in Zerrouka preferred the soil type in which it was produced than other.

\section{Conclusion}

Our results show for the first time that the microvariation of the soil coarse texture $(>5,0.2-0.4$, and $0.063-0.2 \mathrm{~mm})$ and the nitrogen level but not that of the soil limestone affect the growth synchronization between the main and lateral roots by controlling the length and thickness of the main root and the production and distribution of lateral root. We have also clearly shown that these soil properties affected the sink/ source relationship of the roots with leaves and the compensation of root growth. These data suggest other studies to better understand how the soil texture and climate affect the key controls of the root system (root thickness and length) in relation to the shoot growth.

\section{Data Availability}

The data used to support the findings of this study are included within the article. 


\section{Disclosure}

The study was performed in the Research Unit "Environment Plant Interaction" of Usmba Fsdm.

\section{Conflicts of Interest}

The authors declare that they have no conflicts of interest.

\section{Acknowledgments}

The authors thank the Ministry of Higher Education of Morocco for funding this study.

\section{References}

[1] C. Arena, L. Santorufo, P. R. Cataletto, V. Memoli, R. Scudiero, and G. Maisto, "Eco-physiological and antioxidant responses of holm oak (Quercus ilex L.) leaves to Cd and Pb,"Water, Air, \& Soil Pollution, vol. 228, p. 459, 2017.

[2] G. Chevalier, Le chêne blanc et le chêne vert, essences truffières par excellence, forêt méditerranienne, 1996.

[3] J. A. Dominguez, R. Planelles, J. A. Rodriguez Barreal, and J. A. Saiz de Omenaca, "The effect of Tuber melanosporum Vitt. Mycorhization on growth, nutrition, and water relations of Quercus petraea Liebl., Quercus faginea Lamk., and Pinus halepensis Mill. seedlings," New Forests, vol. 35, no. 2, pp. 159-171, 2008.

[4] L. G. García-Montero, M. A. Casermeiro, I. Hernando, and J. Hernando, "Effect of active carbonate, exchangeable calcium, and stoniness of soil on Tuber melanosporum carpophore production," New Zealand Journal of Crop and Horticultural Science, vol. 35, no. 1, pp. 139-146, 2007.

[5] MAPA, F de tierras agrícolas, Análisis de su evolución y contribución a la fijación del carbono y al uso racional de la tierra, 374, 2006.

[6] J. A. Oliet and D. F. Jacobs, "Restoring forests: advances in techniques and theory," New Forests, vol. 43, no. 5-6, pp. 535-541, 2012.

[7] J. Peman Garcia, R. M. Navarro Cerrillo, J. L. NicolásPeragón, M. A. Prada Saez, and R. Serrada Hierro, "Produccion y manejo de semillas y plantas forestales," Ecosistemas, vol. 22, no. 1, p. 92, 2014.

[8] IFN3, Tercer Inventario Forestal Nacional, Ministerio de Agricultura, Alimentación y Medio Ambienten, 1997-2007.

[9] J. M. Rey Benayas and A. Camacho-Cruz, "Performance of Quercus ilex saplings planted in abandoned Mediterranean cropland after long-term interruption of their management," Forest Ecology and Management, vol. 194, no. 1-3, pp. 223233, 2004.

[10] M. Uscola, K. F. Salifu, J. A. Oliet, and D. F. Jacobs, “An exponential fertilization dose-response model to promote restoration of the Mediterranean oak Quercus ilex," New Forests, vol. 46, no. 5-6, pp. 795-812, 2015.

[11] Y. Sheng, H. Wang, M. Wang et al., "Effects of soil texture on the growth of young apple trees and soil microbial community structure under replanted conditions," Horticultural Plant Journal, vol. 6, no. 3, pp. 123-131, 2020.

[12] J. J. Hamer, E. J. Veneklaas, M. Renton, and P. Poot, "Links between soil texture and root architecture of eucalyptus species may limit distribution ranges under future climates," Plant Soil, vol. 403, no. 1-2, pp. 217-229, 2015.

[13] A. Mohamed, A. Stokes, Z. Mao et al., "Linking above- and belowground phenology of hybrid walnut growing along a climatic gradient in temperate agroforestry systems," Plant Soil, vol. 424, no. 1-2, pp. 103-122, 2017.

[14] P. Thaler and L. Pagès, "Root apical diameter and root elongation rate of rubber seedlings (Hevea brasiliensis) show parallel responses to photoassimilate availability," Physiologia Plantarum, vol. 97, no. 2, pp. 365-371, 1996.

[15] M. Willaume and L. Pagès, "How periodic growth pattern and source/sink relations affect root growth in oak tree seedlings," Journal of Experimental Botany, vol. 57, no. 4, pp. 815-826, 2006.

[16] P. B. Reich, R. O. Teskey, P. S. Johnson, and T. M. Hinckley, "Periodic root and shoot growth in oak," Forest Science, vol. 26 , pp. $590-598,1980$.

[17] R. Harmer, "Relation of shoot growth phases in seedling oak to development of the tap root, lateral roots and fine root tips,” New Phytologist, vol. 115, no. 1, pp. 23-27, 1990.

[18] L. Pagès and V. Serra, "Growth and branching of the taproot of young oak trees-a dynamic study," Journal of Experimental Botany, vol. 45, no. 9, pp. 1327-1334, 1994.

[19] V. Rozas and L. Sampedro, "Soil chemical properties and dieback of Quercus robur in Atlantic wet forests after a weather extreme," Plant and Soil, vol. 373, no. 1-2, pp. 673-685, 2013.

[20] P. S. Nobel, "Ecophysiology of roots of desert plants, with special emphasis on agaves and cacti," in Plant Roots: The Hidden Half, Y. Waisel, A. Eshel, and U. Kafkafi, Eds., Marcel Dekker, pp. 823-844, New York, NY, USA, 1991.

[21] E.-D. Schulze, N. C. Turner, D. Nicolle, and J. Schumacher, "Leaf and wood carbon isotope ratios, specific leaf areas and wood growth of eucalyptus species across a rainfall gradient in Australia," Tree Physiology, vol. 26, no. 4, pp. 479-492, 2006.

[22] N. C. Turner, E.-D. Schulze, D. Nicolle, and I. Kuhlmann, "Growth in two common gardens reveals species by environment interaction in carbon isotope discrimination of Eucalyptus,” Tree Physiology, vol. 30, no. 6, pp. 741-747, 2010.

[23] P. Poot and E. J. Veneklaas, "Species distribution and crown decline are associated with contrasting water relations in four common sympatric eucalypt species in southwestern Australia," Plant and Soil, vol. 364, no. 1-2, pp. 409-423, 2013.

[24] L. H. Wiecheteck, N. F. B. Giarola, R. P. de Lima, C. A. Tormena, L. C. Torres, and A. L. de Paula, "Comparing the classical permanent wilting point concept of soil $(-15,000 \mathrm{hPa})$ to biological wilting of wheat and barley plants under contrasting soil textures," Agricultural Water Management, vol. 230, Article ID 105965, 2020.

[25] A. Bacq-Labreuil, J. Crawford, S. J. Mooney, A. L. Neal, and K. Ritz, "Phacelia (Phacelia tanacetifolia Benth.) affects soil structure differently depending on soil texture," Plant and Soil, vol. 441, no. 1-2, pp. 543-554, 2019.

[26] M. Rafique, I. Ortas, I. A. M. Ahmed et al., "Potential impact of biochar types and microbial inoculants on growth of onion plant in differently textured and phosphorus limited soils," Journal of Environmental Management, vol. 247, pp. 672-680, 2019.

[27] A. Buras, U. Sass-Klaassen, I. Verbeek, and P. Copini, "Provenance selection and site conditions determine growth performance of pedunculate oak," Dendrochronologia, vol. 61, Article ID 125705, 2020.

[28] R. A. Viscarra Rossel, B. Minasny, P. Roudier, and A. B. McBratney, "Colour space models for soil science," Geoderma, vol. 133, no. 3-4, pp. 320-337, 2006.

[29] A. Walkley and I. A. Black, "An examination of the Degtjareff method for determining organic carbon in soils: effect of variations in digestion conditions and of inorganic soil constituents," Soil Science, vol. 63, no. 4, pp. 251-263, 1934. 
[30] M. Berthelot, Violet d'aniline. Répertoire de Chimie Appliquée, Société Chimique de Paris, vol. 284, Paris, France, 1895.

[31] J. Kjeldahl, "Neue methode zur bestimmung des stickstoffs in organischen körpern," Fresenius' Zeitschrift für Analytische Chemie, vol. 22, no. 1, pp. 366-382, 1883.

[32] L. Martin Rubio, "Carbon dioxide titration method for soil respiration measurements," Bachelor's thesis, Tampere University of Applied Sciences, 2017.

[33] S. J. Blott and K. Pye, "Gradistat: a grain size distribution and statistics package for the analysis of unconsolidated sediments," Earth Surface Processes and Landforms, vol. 26, no. 11, pp. 1237-1248, 2001.

[34] R. N. Fernandez, D. G. Schulze, D. L. Coffin, and G. E. Van Scoyoc, "Color, organic matter, and pesticide adsorption relationships in a soil landscape," Soil Science Society of America Journal, vol. 52, no. 4, pp. 1023-1026, 1988.

[35] D. G. Schulze, J. L. Nagel, G. E. Van Scoyoc, T. L. Henderson, M. F. Baumgardner, and D. E. Stott, "Significance of organic matter in determining soil colors," Soil Color, vol. 31, pp. 71-90, 1993.

[36] S. D. Anthony, F. J. Douglass, E. W. Kevyn, and K. D. B. Zonda, "Organic matter added to bareroot nursery beds influences soil properties and morphology of Fraxinus pennsylvanica and Quercus rubra seedlings," New Forests, vol. 31, no. 2, pp. 293-303, 2006.

[37] M. Conforti, F. Lucà, F. Scarciglia, G. Matteucci, and G. Buttafuoco, "Soil carbon stock in relation to soil properties and landscape position in a forest ecosystem of southern Italy (Calabria region)," Catena, vol. 144, pp. 23-33, 2016.

[38] A. P. Fernández-Getino, J. L. Alonso-Prados, and M. I. SantínMontanyá, "Soil carbon characterization along the profile of two forest soils under Quercus pyrenaica," Journal of Forestry Research, vol. 31, no. 2, pp. 591-600, 2018.

[39] S. Freixes, M.-C. Thibaud, F. Tardieu, and B. Muller, "Root elongation and branching is related to local hexose concentration in Arabidopsis thaliana seedlings," Plant, Cell \& Environment, vol. 25, no. 10, pp. 1357-1366, 2002.

[40] K. Jung, M. Duan, J. House, and S. X. Chang, "Textural interfaces affected the distribution of roots, water, and nutrients in some reconstructed forest soils in the Athabasca oil sands region," Ecological Engineering, vol. 64, pp. 240-249, 2014.

[41] N. Clarke, P. Gundersen, U. Jönsson-Belyazid et al., "Influence of different tree-harvesting intensities on forest soil carbon stocks in boreal and northern temperate forest ecosystems," Forest Ecology and Management, vol. 351, pp. 9-19, 2015.

[42] F. E. Allison, Soil Organic Matter and Its Role in Crop Production, Elsevier Scientific Publishing Company, New York, NY, USA, 1973.

[43] A. Agnelli, L. Massaccesi, M. De Feudis, S. Cocco, F. Courchesne, and G. Corti, "Holm oak (Quercus ilex L.) rhizosphere affects limestone-derived soil under a multicentennial forest," Plant and Soil, vol. 400, no. 1-2, pp. 297-314, 2016.

[44] J. R. Helliwell, C. J. Sturrock, S. Mairhofer et al., "The emergent rhizosphere: imaging the development of the porous architecture at the root-soil interface," Scientific Reports, vol. 7, p. 14875, 2017.

[45] S. L. Martin, S. J. Mooney, M. J. Dickinson, and H. M. West, "Soil structural responses to alterations in soil microbiota induced by the dilution method and mycorrhizal fungal inoculation," Pedobiologia, vol. 55, no. 5, pp. 271-281, 2012.
[46] D. S. Feeney, J. W. Crawford, T. Daniell et al., "Three-dimensional microorganization of the soil-root-microbe system," Microbial Ecology, vol. 52, no. 1, pp. 151-158, 2006.

[47] M. Cambi, Y. Hoshika, B. Mariotti et al., "Compaction by a forest machine affects soil quality and Quercus robur L. seedling performance in an experimental field," Forest Ecology and Management, vol. 384, pp. 406-414, 2017. 